удк 658.6

И. С. Черняк

Иркутский национальный исследовательский технический университет,

г. Иркутск, Российская федераиия

В. Ю. Конюхов

Иркутский национальный исследовательский технический университет,

г. Иркутск, Российская Федерация

\title{
ЛОГИСТИЧЕСКИЙ ПОДХОД РАЗРЕШЕНИЯ ПРОБЛЕМ С ПОМОЩЬЮ ИНСТРУКЦИЙ ПРИ ПРИЕМКЕ, ОТПУСКЕ ТОВАРОВ ПО КОЛИЧЕСТВУ И КАЧЕСТВУ
}

\begin{abstract}
АНнотАция. Грамотное управление приемкой и отпуском товарной продукции на производстве и в торговле, а также хранение по количеству и качеству товара при соблюдении всех нормативных актов - основные требования экономической политики. В статье отмечается, что работа по приемке и отпуску товаров с использованием инструкций П-6 и П-7 вызывает сомнения у менеджеров предприятий производства и торговли в связи с их утверждением еще в советское время (1965 и 1966 гг. соответственно). Логистика позволяет экономно управлять финансовыми и материальными ресурсами, поэтому в условиях кризиса и санкций главными мероприятиями, на которые следует обратить внимание, является соблюдение следующих условий: исключение попадания товаров ненадлежащего качества; обеспечение всех требований, установленных правилами; сокращение непроизводительных расходов. В настоящее время рекомендуется доработать утвержденные в советское время инструкции с учетом требований сегодняшнего дня, а руководству арбитражных судов собрать юристов крупных организаций промышленности и торговли.

кЛЮчЕВЫЕ слОВА. Логистический подход; инструкция; приемка товаров; отпуск товаров; качество; договор; логистика снабжения; затраты; услуги; поставка; эффективность; логистика складирования; кризис; санкции; запасы; предпринимательство, статья кодекса.
\end{abstract}

ИНФОРМАЦИЯ О СТАТЬЕ. Дата поступления 4 февраля 2016 г.; дата принятия к печати 25 февраля 2016 г.; дата онлайн-размещения 29 марта 2016 г.

I. S. Chernyak

Irkutsk National Research State Technical University, Irkutsk, Russian Federation

V. Yu. Konyukhov

Irkutsk National Research State Technical University,

Irkutsk, Russian Federation

\section{LOGISTICAL APPROACH TO SOLVING PROBLEMS USING INSTRUCTIONS FOR GOODS RECEIPT AND DISPATCH IN REGARD OF QUALITY AND QUANTITY}

\begin{abstract}
Competent management of goods receipt and dispatch in industry and trade, as well as storage of goods according to quantity and quality in compliance with all necessary regulatory acts are the key requirements of economic policy. The article notes that activities in goods receipt and dispatch using the P-6 and P-7 instructions cause doubts in managers of industrial and trade businesses in the context of their approval in the Soviet period (1965 and 1966, respectively). Logistics allows to efficiently manage financial and materials resources, that's why, in terms of crises and sanctions the main
\end{abstract}

\section{Baikal Research Journal}


measures to pay attention to is to observe the following conditions: exclusion of poor quality goods; compliance with all requirements set by the rules; reduction of unproductive expenses.

KEYWORDS. Logistics approach; instruction; goods receipt; goods dispatch; quality; contract; supply logistics; costs; services; supply; efficiency; storage logistics; crisis; sanctions; resources; entrepreneurship, code article.

ARTICLE INFO. Received February 4, 2016; accepted February 25, 2016; available online March 29, 2016.

Проблемы - это на самом деле возможности, появляющиеся в рабочей одежде.

Генри Кайзер

Невозможно сделать работу, не нарушая инструкций. Выполнение работы не оправдывает нарушения инструкций.

Из сборника «Законы Мерфи»

Экономика есть искусство удовлетворять безграничные потребности при помощи ограниченных ресурсов.

Из книги «Цитаты Питера»

Функция процедуры приемки товара и по сей день остается краеугольным камнем в отношениях между поставщиком и покупателем. Одним из способов, чтобы обезопасить себя от недоразумений, связанных с приемкой товара, - это следовать инструкциям П-6 и П-7 [1-4]. Серьезной причиной возникновения конфликтных ситуаций по поводу качества или количества принимаемой продукции, приводящих зачастую даже в арбитражный суд, может стать именно незнание и непонимание указанных инструкций в организациях, получающих товароматериальные ценности в производство или на склад для хранения.

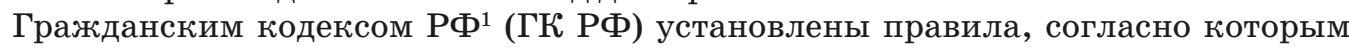
в сделках купли-продажи или поставки товар должен быть передан покупателю в надлежащем количестве, а также надлежащего качества (ст. 469). Обязанность покупателя проверить полученный товар по качеству и количеству в порядке и в сроки, установленными правовыми актами, договором и обычаями делового оборота регламентирует п. 2 ст. 513 ГК РФ. Для покупателя и поставщика важно определить момент перехода рисков, когда они должны произвести определенные действия на бесконфликтное получение товара.

В ст. 474 ГК РФ установлено, чтобы порядок и условия проверки качества товара, которые будут применяться поставщиком и покупателем, были одними и теми же, а также чтобы они соответствовали правилам, установленным законом, иными правовыми актами или обязательными требованиями государственных стандартов, т. е. согласование условий и порядок приемки товаров по качеству должны быть прописаны в договоре поставки. Чем грамотнее и точнее в договоре будет описан весь процесс, начиная с получения товара от поставщика или перевозчика и заканчивая составлением актов и рекламаций, тем меньше у сторон шансов стать участниками судебного разбирательства [5-7].

Ни одно предприятие любой формы собственности (государственное или частное) не обходится без снабжения различными материалами: сырья, готовой продук-

${ }^{1}$ Гражданский кодекс Российской Федерации (часть вторая) : федер. закон от 26 янв. 1996 г. № 14-ФЗ // Собрание законодательства Российской Федерации. 1996. № 5. Ст. 410.

\section{Baikal Research Journal}


ции, полуфабрикатов, запчастей, вспомогательных материалов, которыми занимаются службы снабжения.

Логистика снабжения как функциональная область логистики основывается в первую очередь на логистических принципах: снабжение, затраты, логистическая координация и интеграция, оптимизация и т. д.

Снабжение - процесс, реализуемый организационной единицей, которая, будучи частью интегрированной цепи поставок, отвечает за приобретение всех материалов и услуг требуемого качества в необходимом количестве, в нужное время, по наименьшей общей стоимости с сохранением должного уровня сервиса, а также за управление поставщиками, на основе чего организация получает конкурентное преимущество и реализует корпоративную стратегию [1-3].

Главные цели процесса снабжения:

1. Оптимизация затрат на снабжение.

2. Обеспечение надежности и непрерывности материального потока и сервисного потока (услуг), необходимых для функционирования организации.

3. Поддержание и повышение качества процесса снабжения на основе модернизации и рационализации.

4. Формирование и управление базой поставщиков.

5. Управление взаимоотношениями с поставщиками.

6. Достижение гармоничных, продуктивных рабочих отношений с функциональными подразделениями организации, являющимися внутренними клиентами отдела снабжения.

Отметим, что зависимость от этапа развития каждой конкретной организации эффективности процесса снабжения и его вклад в повышении конкурентноспособности организации различны [8-10]. Происходят изменения в сфере производства компьютеров и коммуникационных технологий, что способствует осуществлению логистического подхода, построенного на множестве учетных элементов и оперирующего большими данными.

Обозначим категории данных, с которыми приходится иметь дело в логистике:

1. Местоположение каждого клиента.

2. Объем каждого заказа.

3. Территориальное размещение производства, складов и центров распределения.

4. Стоимость транспортных перевозок от каждого склада или завода до каждого клиента.

5. Существующие транспортные агентства и уровень сервиса, который они предлагают.

6. Местоположение поставщиков.

7. Уровень запасов товаров, в каждый момент времени имеющихся на складах и в центрах распределения.

В логистике приходится иметь дело с таким объемом информации, анализировать который без компьютерной техники практически невозможно.

Логистика - это классический пример системного подхода к проблемам бизнеса. С точки зрения бизнеса, системный подход означает, что цели предприятия (компании) можно достигнуть в результате реализации основных функциональных миссий фирмы (маркетинг, производство и финансы) [9; $11 ; 12]$. Цель логистики состоит в координации физического распределения и менеджмента материалов для экономии затрат, повышения уровня обслуживания.

По мере развития торговли и промышленности возникло понимание, что складирование (хранение) и соответствующие ему иные услуги (разгрузка, погрузка, приемка, сортировка и пр.) могут быть отдельным видом предпринимательства [4]. Системы хранения и переработки - это важнейшие элементы логистических си-

\section{Baikal Research Journal}


стем. Они позволяют преодолеть временные, пространственные, количественные и качественные несоответствия между наличием и потребностью в материалах в процессе производства, реализации и потребления. Известно, что 95-98 \% времени, в течение которого материал находится на любом предприятии, приходится на выполнение транспортно-складских работ.

В периоды предыдущих кризисов $(1998,2008)$ и на сегодняшний день замечено, что на логистические услуги руководители производственных и торговых предприятий не уделяют внимание соблюдению требований логистического подхода.

При составлении проекта договора купли-продажи или поставки обязательно следует включить в статью, описывающую процесс получения и приемки товара покупателем, в части, не противоречащей гражданскому законодательству, и с учетом правил, установленных самим договором, указание на применение норм, содержащихся в двух документах: Инструкция о порядке приемки продукции производственно-технического назначения и товаров народного потребления по количеству ${ }^{2}$ (далее - инструкция П-6); Инструкция о порядке приемки продукции производственно-технического назначения и товаров народного потребления по качеству ${ }^{3}$ (далее - инструкция П-7). Хозяйственная и судебно-арбитражная практика признают инструкции П-6 и П-7 одним из существенных компонентов делового оборота.

Следует в виду, что пленум Высшего Арбитражного Суда РФ закрепил принцип, согласно которому положения инструкций П-6 и П-7 о приеме товара по количеству и качеству могут применяться покупателем только в том случае, если это предусмотрено договором поставки ${ }^{4}$. Не лишним следует также учитывать соотношение инструкций П-6 и П-7 и с другими нормативными документами, например, государственными и отраслевыми стандартами, нормы которых применяются даже в случае расхождения с инструкциями. Особенно нельзя пренебрегать знаниями нормативных актов, которые помогут правильно и качественно осуществить приемку и отгрузку товароматериальных ценностей, исключив колоссальные потери на производстве и торговле $[10 ; 12 ; 13]$.

Многие предприниматели и юристы активно принимают участие в форумах и семинарах или общаются между собой о возможности применения инструкций П-6 и П-7, а также как их использовать при приемке импортных товаров, чтобы грамотно составить договор. Поскольку приемка импортных товаров имеет свои особенности, а существующие требования не определены контрактом товаров по количеству и качеству, то требуется обновление составление рекламационных актов, утвержденных Госарбитражем СССР. По нашему мнению, настало время переработать эти правовые документы с условиями требований сегодняшнего дня и дать возможность руководителям и юристам не сомневаться в их действиях и думать, что инструкции П-6 и П-7 устарели.

Таким образом, бережливо и рационально управляя материальными запасами сырья, материалов, полуфабрикатов, запчастями), логистика способствует уменьшению общих затрат, снижению цены товаров и стратегическому улучшению позиций компаний на рынке.

\footnotetext{
${ }^{2}$ Инструкция о порядке приемки продукции производственно-технического назначения и товаров народного потребления по количеству [Электронный ресурс] : утв. постановлением Госарбитража СССР от 15 июня 1965 г. № П-6 // СПС «КонсультантПлюс».

${ }^{3}$ Инструкция о порядке приемки продукции производственно-технического назначения и товаров народного потребления по качеству [Электронный ресурс] : утв. постановлением Госарбитража СССР от 25 апр. 1966 г. № П-7 // СПС «КонсультантПлюс» .

${ }^{4}$ О некоторых вопросах, связанных с применением Положений Гражданского кодекса Российской Федерации о договоре поставки [Электронный ресурс] : постановление пленума Высшего Арбитражного Суда РФ от 22 окт. 1997 г. № 18 // СПС «КонсультантПлюс» .
}

\section{Baikal Research Journal}




\section{Список использованной литературы}

1. Логистика и управление цепями поставок. Теория и практика. Основные и обеспечивающие функциональные подсистемы логистики : учебник / под ред. Б. А. Аникина, Т. А. Родкиной. - М. : Проспект, 2015. - 608 с.

2. Современная логистика : пер. с англ. / Д. Л. Вордлоу, Д. Ф. Вуд, Д. Джонсон, П. Р. Мерфи. - 7-е изд. - М. : Вильямс, 2002. - 624 с.

3. Волгин В. В. Логистика хранения товаров : практ. пособие / В. В. Волгин. - М. : Дашков и $\mathrm{K}^{0}, 2015 .-368$ с.

4. Волгин В. В. Логистика приемки и отгрузки товаров : практ. пособие / В. В. Волгин. М. : Дашков и $\mathrm{K}^{0}, 2007 .-460$ с.

5. Афанасенко И. Д. Логистика снабжения : учебник / И. Д. Афанасенко, В. В. Борисова. - СПб. : Питер, 2010. - 336 с.

6. Логистика / В. В. Дыбская, Е. И. Зайцев, В. И. Сергеев, А. Н. Стерлигов ; под ред. В. И. Сергеева. - М. : Эксмо, 2013. - 944 с.

7. Сергеев В. И. Логистика снабжения : учебник / В. И. Сергеев, И. П. Эльяшевич. - М. : Рид Групп, 2011. - 416 с.

8. Степанов В. И. Логистика : учеб. для бакалавров / В. И. Степанов. - М. : Проспект, 2016. $-488 \mathrm{c.}$

9. Корпоративная логистика. 300 ответов на вопросы профессионалов / под ред. В. И. Сергеева. - М. : Инфра-М, 2004. - 976 с.

10. Шапиро Дж. Моделирование цепи поставок / пер. с англ. под ред. В. С. Лукинского. - СПб. : Питер, 2006. - 720 с.

11. Галимова Е. О. Куда уходят деньги, или логистика для предпринимателей : практ. пособие / Е. О. Галимова. - М. : КНОРУС, 2009. - 224 с.

12. Галанов В. А. Логистика : учебник / В. А. Галанов. - М. : Форум : Инфра-М, 2007. -272 c.

13. Боутеллир Р. Стратегия и организация снабжения : пер с немец. / Р. Боутеллир, Д. Корстен ; под ред. Н. Ф. Титюхина. - М. : КИА центр, 1996. — 128 с.

\section{References}

1. Anikin B. A., Rodkina T. A. (eds). Logistika i upravlenie tsepyami postavok. Teoriya i praktika. Osnovnye i obespechivayushchie funktsional'nye podsistemy logistiki [Logistics and management of supply chains. Theory and practice. Major and provisional functional subsystems of logistics]. Moscow, Prospect Publ., 2015. 608 p.

2. Wardlow Daniel L., Wood Donald F., Johnson James C., Murphy Paul R., jr. Contem porary Logistics. $7^{\text {th }}$ ed. New York, Chapman \& Hall, 1999. 586 p. (Russ. ed.: Wardlow D. L., Wood D. F., Johnson J. C., Murphy P. R. Sovremennaya logistika. $7^{\text {th }}$ ed. Moscow, Williams Publ., 2002. 624 p.).

3. Volgin V. V. Logistika khraneniya tovarov [Logistics of commodity storage]. Moscow, Dashkov i K ${ }^{0}$ Publ., 2015. 368 p.

4. Volgin V. V. Logistika priemki i otgruzki tovarov [Logistics of receipt and dispatch of goods]. Moscow, Dashkov i $\mathrm{K}^{0} \mathrm{Publ}, 2007.460 \mathrm{p}$.

5. Afanasenko I. D., Borisova V. V. Logistika snabzheniya [Supply logistics]. Saint Petersburg, Piter Publ., 2010. 336 p.

6. Dybskaya V. V., Zaitsev E. I., Sergeev V. I., Sterligov A. N. Logistika [Logistics]. Moscow, Eksmo Publ., 2013. 944 p.

7. Sergyeev V. I., El'yashevich I. P. Logistika snabzheniya [Supply Logistics]. Moscow, Red Group Publ., 2011. 416 p.

8. Stepanov V. I. Logistika [Logistics]. Moscow, Prospect Publ., 2016. 488 p.

9. Sergeyev V. I. (ed.). Korporativnaya logistika. 300 otvetov na voprosy professionalov [Corporative logistics. 300 answers to questions of professionals]. Moscow, Infra-M Publ., 2004. 976 p.

10. Shapiro Jeremy F. Modelling the Supply Chain. Duxbury Press, Pacific Grove, California, 1998. 586 p. (Russ. ed.: Shapiro J. Modelirovanie tsepi postavok. Saint Petersburg, Piter Publ., 2006. 720 p.).

11. Galimova E. O. Kuda ukhodyat den'gi, ili logistika dlya predprinimatelei [Where does money go, or logistics for busisnessmen]. Moscow, Knorus Publ., 2009. 224 p.

\section{Baikal Research Journal}


12. Galanov V. A. Logistika [Logistics]. Moscow, Forum Publ., Infra-M Publ., 2007. 272 p.

13. Boutellir R., Corsten D. Strategiya i organizatsiya snabzheniya [Strategy and commodity management]. Moscow, KIA centre Publ., 1996. 128 p.

\section{Информация об авторах}

Черняк Илья Самуилович - кандидат экономических наук, профессор, кафедра управления промышленными предприятиями, Иркутский национальный исследовательский технический университет, 664074, г. Иркутск, ул. Лермонтова, 83, e-mail: e12@istu.edu.

Конюхов Владимир Юрьевич - кандидат технических наук, профессор, кафедра управления промышленными предприятиями, Иркутский национальный исследовательский технический университет, 664074, г. Иркутск, ул. Лермонтова, 83, e-mail: e12@istu.edu.

\section{Authors}

Ilya S. Chernyak - PhD in Economics, Professor, Chair of Industrial Enterprise Management, Irkutsk National Research State Technical University, 83 Lermontov St.,664074, Irkutsk, Russian Federation; e-mail: e12@istu.edu.

Vladimir V. Konyukhov - PhD in Engineering, Professor, Chair of Industrial Enterprise Management, Irkutsk National Research State Technical University, 83 Lermontov St., 664074, Irkutsk, Russian Federation; e-mail: e12@istu.edu.

\section{Библиографическое описание статьи}

Черняк И. С. Логистический подход разрешения проблем с помощью инструкций при приемке, отпуске товаров по количеству и качеству / И. С. Черняк, В. Ю. Конюхов // Baikal Research Journal. — 2016. — T. 7, № 2. - DOI : 10.17150/2411-6262.2016.7(2).15.

\section{Reference to article}

Chernyak I. S., Konyukhov V. Yu. Logistical approach to solving problems using instructions for goods receipt and dispatch in regard of quality and quantity Baikal Research Journal, 2016, vol. 7, no. 2. DOI: 10.17150/2411-6262.2016.7(2).15. (In Russian).

\section{Baikal Research Journal}

